\title{
Papers of the
}

East-West Population Institute, no. 35

\section{Fertility socialization research in the United States:}

a progress report

\author{
by Susan O. Gustavus
}


THE EAST-WEST CENTER is a national educational institution established in Hawaii by the U.S. Congress in 1960 to "promote better relations and understanding between the United States and the nations of Asia and the Pacific through cooperative study, training and research."

Each year the East-West Center brings together more than 1,500 men and women from the many nations and cultures of these regions. They work and study together while exchanging ideas and experiences in cooperative programs seeking solutions to important problems of mutual concern to East and West. For each participant from the United States in Center programs, two participants are sought from the more than 60 countries and territories in Asia and the Pacific area.

Five institutes with international, interdisciplinary academic and professional staffs conduct the East-West Center's problem-oriented programs. East-West areas on which Center programs are focused include communication across national barriers, culture and language learning, food systems, population dynamics, and technological adaptation in developmental processes aimed at improving the quality of life. Each year the Center awards a limited number of Open Grants for graduate degree education and innovative research by Senior Fellows in areas not encompassed by institute programs.

The Center is directed by the Board of Governors of a public, non-profit educational corporation-known as "The Center for Cultural and Technical Interchange Between East and West, Inc." - created by the Hawaii State Legislature in 1975. The U.S. Congress provides basic funding for Center programs and a variety of scholarships, fellowships, internships and other awards. Additional cost-sharing of programs and participants is worked out with Asian/Pacific governments, regional agencies, private enterprise and foundations. The Center is situated on land adjacent to and provided by the University of Hawaii, which conducts classes and grants degrees for degree-seeking East-West Center students who also are involved in the Center's problem-oriented programs.

THE EAST-WEST POPULATION INSTITUTE, established as a unit of the East-West Center in 1969 with the assistance of a grant from the Agency for International Development, carries out multidisciplinary research, training, and related activities in the field of population, placing emphasis on economic, social, psychological, and environmental aspects of population problems in Asia, the Pacific, and the United States. 


\title{
Fertility socialization research in the United States: a progress report
}

\author{
by Susan O. Gustavus
}

Number 35 - July 1975

PAPERS OF .THE EAST-WEST POPULATION INSTITUTE 
SUSAN O. GUSTavUS is Associate Professor of Sociology at the University of Cincinnati.

\section{Library of Congress Cataloging in Publication Data}

Gustavus, Susan O

Fertility socialization research in the United States.

(Papers of the East-West Population Institute ; no. 35)

Bibliography: p. 17-19.

1. Population research-United States. 2. Family size-Research-United States. 3. SocializationResearch-United States. I. Title. II. Series:

East-West Population Institute. Papers of the East-West

Population Institute; no. 35.

HB850.5.U5G87 301.32'07'2073 75-22305 


\section{CONTENTS}

Preface $v$

Abstract $\quad 1$

Theoretical beginnings . 2

The methodology 4

The findings 7

Theoretical relevance $\quad 12$

Future directions $\quad 14$

References $\quad 17$ 

PREFACE

The author wishes to thank Lawrence A. Brown of Ohio State University for his time, valuable criticisms, and encouragement during preparation of earlier versions of this paper. In addition, appreciation is extended to James Palmore of the East-West Population Institute, who organized the conference at which this paper was originally delivered. Finally, thanks are again due Charles B. Nam, Florida State University, the real origina-. tor of the author's work in this area. 
.. 
ABSTRACT This paper reviews the findings of fertility socialization studies in the United States, their rationale, theoretical underpinnings in the work of Westoff and Potvin, and their methodological achievements and problems. Specifically, the findings on the relationship of children's family size preferences to size of family of orientation, sex, race, religion, socioeconomic status, aspirations, and other variables are examined and related to earlier theoretical hypotheses. This review indicates that three approaches have been used in studying the origin of children's family size preferences: the correlational approach, the conscious-sources approach, and the complementary interview. Two strategies, cross-sectional and longitudinal, have been used in assessing stability of these preferences. Finally, the paper offers suggestions for future directions in fertility socialization research and theory.

A growing amount of literature would seem to indicate that a new approach to the study of demographic phenomena has emerged. Now labeled "population socialization," this subfield focuses on those processes by which new members of the society take on any and all ideas and behaviors related to population processes. The study of population socialization recognizes that some learning of attitudes, facts, or behaviors relevant to fertility, mortality, migration, population size, composition, growth, or distribution occurs before the adult years; modifying and limiting the impact of later adult learning.

Within this broad range of potential topics, the empirical literature to date has emphasized fertility attitude learning, or more specifically, factors related to the formation of family size preferences among children and adolescents. The processes of factual learning about population, methods for transmittal of behaviors, and the learning of at titudes toward migration, mortality, or related cultural phenomena have all been relatively neglected.

This paper will focus on fertility socialization studies in the United States, their theoretical underpinnings, me thodological achievements and problems, findings, and theoretical relevance. Finally, the paper will suggest directions for research in this area. It is hoped that such an overview will serve two purposes: what is known about fertility socialization will be more sharply focused for students of reproductive bchavior, and the history of these studies may then be used as a guide for population socialization researchers interested in nonfertility topics. 


\section{THEORETICAL BEGINNINGS}

While scattered studies existed prior to 1966, Westoff and Potvin (1967) gave fertility socialization research a meaningful place in population studies. Faced with negative results in an attempt to show the impact of college education on women's family size ideals, these authors hypothesized that family size preferences were formed much earlier' than the college years. Labeling their work "a theory of the origins and stability of family size ideals," Westoff and Potvin listed factors they believed related to these phenomena.

Number of siblings in a girl's family, size of the families of her reference groups, religion, ethnicity, and social class were said to be influential in the origins of family size preferences. Implicit in this list was the notion that combinations of these factors could exert interactive impact, as for Irish Catholic middle-class girls. Continuity in reference groups was seen as the primary variable explaining preference stability, with examples of discontinuity including rural-to-urban migration, social mobility, or changing educational settings. Westoff and Potvin also named the 8- to 13-year-old age group as appropriate for study. That suggestion, along with the hypotheses generated from their list of factors, quickly became guides for subsequent empirical effort.

Questions about the theoretical and practical utility of such research were soon raised. Would studies of children measure anything other than the fantasies of youth? More generally, were children's family size preferences stable or were changes in them patterned so that measuring early preferences would contribute to explanation or prediction of subsequent fertility behavior?

At least three justifications for the use of young samples have appeared in the literature. First, the child population may represent a better setting in which to study family size preferences than does the adult population, simply because these preferences are undisturbed by the reality of fertility. Westoff and Potvin make this point:

It is some consolation to reflect that the variable on which we are focusing is the size of family preferred rather than the size of family achieved. As such, it should be theoretically more sensitive to the factors discussed above than actual fertility, which involves, in addition to desired family size, qualitatively different dimensions such as physiological factors, availability of fertility control techniques, another person and his fertility values, and a not inconsiderable element of chance (1967, p. 126).

Specifically with regard to a sample of children, Paterson notes: 
It can be argued, then, that there are such questions which are most appropriately posed to a non-married, younger population, and that some theoretical issues might be more sensitively assessed within such a population, since fertility orien. tations are separated from actual fertility, and since mobility aspirations can, by and large, be disentangled from actual socio-economic achievement (1972, p. 232).

A second rationale is that, whether an early notion about appropriate family size is identical to eventual fertility. or not, there is reason to believe that it is at least one important variable influencing later fertility. While early ideas may change, the very process by which they originate and are modified needs to be incorporated in a more complete model of fertility behavior. This point is equally appealing to those who construct fertility models and those who would intervene in the process of family formation. Russo and Brackbill illustrate this latter interest:

The population programmer has a long way to go in order to have an impact on population growth. Early socialization, especially with respect to sex-role conception and religious values, appears to play a major role in the development of family-size preferences. Siudies of how such socialization affects motivation for parenthood and perceived functions of children are logically of high priority for the action programmer (1973, p. 402).

Thirdly, empirical findings have been employed to make a "face validity" argument of the utility of children's responses. Variables related to actual fertility are shown to be related to children's family size preferences. Paterson illustrates this rationale:

Examination of the means of the fertility measures tends to support Westoff and Potvin's contention that size of family of orientation and socio-economic and religious group memberships are relevant determinants of fertility norms. These are scarcely novel conclusions, since such relationships have been shown to hold for the adult population on numerous occasions. ... On the other hand, the repetition may be of some significance in itself, at least in resolving some of the doubts as to whether pre-adult fertility preferences are more than mere fantasies (1972, p. 236).

A sizable literature has now emerged employing one or more of these rationales. This work has seldom been guided by a general socialization theory, however, and has not been particularly cumulative. In addition, with the possible exception of Russo and Brackbill (1973), there is no summary of what is known about the Westoff-Potvin framework, or even about discrete variables and their relationships to fertility socialization. That task will be addressed in the remainder of this paper. 


\section{THE METHODOLOGY}

The age of children included in fertility socialization studies is usually defined by their grade in school, since most data are gathered through the educational system. The children range from sixth graders to seniors in college. This sampling procedure, while convenient, has virtually eliminated the school dropout from fertility socialization studies. A few investigations include complementary interviews with spouses or mothers of young people (Hendershot, 1967; Darney, 1970).

The size of the sample varies from fewer than 200 to the 15,000 American college women interviewed by Westoff and Potvin. While few of the samples are random, the geographical locations represented are widely distributed and include Louisiana, southern Georgia and northern Florida, New Jersey, northwestern Ohio, New York, Texas, Philadelphia, and Seattle.

Researchers have alternately used expected, ideal, desired, wanted, and anticipated fertility as dependent variables. Most of the questions measuring these variables are phrased with a future referent, such as "when you get married," or "when you have your own family." One recent study (Presser, 1974) used a retrospective question concerning family size desires at age 16, asked of women who had already borne their first children.

Even where familiar forms of family size questions are used, the exact phrasing has not always followed the traditions apparent in the demographic literature. The necessity to appease parents, teachers, and school boards, or to make the question maximally simple for youngsters has prompted these variations.

In addition to measuring family size preferences, some studies ask how many children are too many or too few, or similarly, how many children make a family too large or too small. Responses to these items have usually been interpreted as defining a normative range of acceptable fertility.

Most fertility socialization studies are cross-sectional in design, including samples which may or may not exhibit age variation. A longitudinal design was used for the Westoff and Potvin study of American college women (Potvin and Burch, 1969; Potvin and Lee, 1974) and the Gustavus and Nam study of southern Georgia and northern Florida youngsters (Gustavus, 1973). But neither of these studies covers a period longer than four years, leaving still unheeded the Westoff and Potvin suggestion that a cohort be followed for ten years.

Many researchers use only means and percentages to present data, 
often without tests of significance. This practice is generally justified by the nonrepresentativeness of the samples from which the data are drawn. Others use path analysis, sign tests, measures of covariance, and similar techniques, of ten with rather poor samples (van Tienhoven et al., 1969; McLaughlin, 1974; Brackbill and Howell, 1974), but also with random samples designed to represent larger populations (Westoff and Potvin, 1967; Paterson, 197.2).

Some of these methodological procedures have been problematic. As in studies of the family size preferences or intentions of adults, questions were raised about the reliability and validity of the measures used. Would children be able to verbalize any kind of family size preference? Even if so, would this number reflect only an on-the-spot idea that had not really been considered before? These questions relate to the theoretical discussion above on the utility of such preferences for model building or practical projection. However, the concern here is methodological: assuming children's preferences to be useful, can they really be measured?

To combat these objections, some questionnaires have asked young people whether they have ever given thought to how many children are desirable for themselves or others. Since the proportion of children reporting prior consideration of this issue has been directly related to age, and the majority of children surveyed in even the six th grade have answered this question affirmatively, some assurance of nonrandom response was obtained. In addition, there has been little refusal or inability to respond to questions soliciting a numerical fanily size preference or intention. Still a third check on the logic of children's responses has been to compare personal family size intentions with how many children would be too many and too few. The reasoning is that if these young respondents are giving meaningful replies, their own preferences should fall somewhere between the family sizes they desigs nate as too large or too small.

Most fertility socialization research does not include formal measures of either reliability or validity, however. Test-retest data are scarce, as is comparison of children's responses on background items with "objective" sources of these data.

A recent study by Brackbill (1974) on reliability problems is of use in population socialization. Brackbill interviewed, and a month later reinterviewed, a sample of 288 students in Washington, D.C., drawn from the ninth and twelf th grades and from the sophomore college level. Her data relate to variations in reliability by content and psychological attributes of questions, and by characteristics of respon- 
dents. On the content dimension, reliability was highest for background information, while lower for family size preferences and population facts. By psychological attributes, Brackbill found reliability was highest for knowledge, while lower for desires and attitudes respectively. Reliability was higher for older, white, and Catholic youngsters but did not vary by sex.

Other disciplines have examined the validity and reliability of children's responses in a variety of contexts. That literature, coupled with the Brackbill work dealing specifically with population items, can be profitably used to indicate expected validity and reliability problems and their solutions.

Even if reliability and validity problems were lessened in fertility socialization research, other difficulties remain. While the locations of studies given above reflect many different areas of the country, good comparison of results in, say, Seattle and northern Florida is impossible. Even if more than one study were available at a given site, different measures of the dependent variable would thwart a comparative effort. It has recently become apparent, for example, that a question asking "How many children do you think you will have when you get married?" may not be at all the same as a question asking "How many children do you want?"

The style of data analysis described above, combined with the lack of a general theoretical framework, has limited what is known about fertility socialization in another way. Since many researchers have chosen to look at a series of two-variable relationships rather than to use multivariate techniques, the relative importance and interactive impacts of factors in producing or modifying family size preferences are unknown. Those who would synthesize are forced to look at the consistency with which two-variable relationships appear in different settings, at different times, for different age groups, and when different dependent variable measures are used.

Finally, cross-sectional data analyzed by age are not the same as cohort data gathered over time (Gustavus, 1973). Even the existing longitudinal data on fertility socialization have been collected during a period of great population publicity and concern. It is not certain whether the findings, particularly on changing size of preferences, are a reflection of aging or of the period.

All of these problems are surmountable and have no inherent relationship to the task undertaken by fertility or population socialization researchers. They are rather a reflection of the embryonic nature of this work at present. 


\section{THE FINDINGS}

The limitations and variations noted above make the task of summarizing.what is known about the process of fertility socialization difficult. Nevertheless, where consistencies emerge in these data they are perhaps the more remarkable. This section will cite three kinds of findings: the size of families given by youngsters, correlates of these family sizes, and results of multivariate analyses. While this presentation of findings is not organized around the Westoff-Potvin formulation on origins and stability of family size preferences, the literature itself does not reflect overt concern with these dimensions. The implications of these findings for the original Westoff-Potvin theory will be examined in a later section of this paper.

\section{Size of Families}

In recent years, the consistency of adult responses to questions on intended, desired, expected, or wanted fertility has been so great that some researchers have hypothesized a norm of family size. The fertility socialization research lends credence to this hypothesis, since, like parents, children cluster heavily in a two-to-four child preference range. Even the youngest children conform to this range, with very few giving "outlandish" numbers as preferred, ideal, intended, etc.

Consensus also emerges in response to questions about how many children are too many or too few. Gene rally, the mean number for "too many" ranges from 5.2 to 5.9 children, while the mean number for "too few" ranges from 1.4 to 2.1 children. These ranges are applicable, for example, to young people surveyed in California (Darney, 1970), New Jersey (Wernick, 1974), and northern Florida and southern Georgia (Gustavus and Nam, 1970).

Even though supported by only two studies with longitudinal data, consistency also seems apparent in the direction of change in family size preferences over time. Both Gustavus (1973) and Potvin and Burch (1969) have found reductions in family size preferences of young people as they grow older. Since the age groups represented, the time of. surveys, and the geographical locations of these studies were widely different, this finding seems the more secure.

\section{Correlates of Family Size}

In summarizing the findings on the relationships of discrete variables to the family sizes given by youngsters, four kinds of information will be supplied: (1) the place of the variable in the original Westoff-Potvin 
list of factors influencing family size preference formation; (2) the amount of attention given the variable in the literature; (3) the consistency of findings relative to the variable; and (4) special information that may be related to measurement practices, definitional variations, or interactions with other variables.

Attempting such a presentation requires ignoring many comparative problems cited earlier. This section will treat the family sizes given by children as the same when, in fact, measurement or conceptual differences occur. In addition, no attempt will be made to weight one finding as more important than another because of sampling practices or measurement choices. The studies reviewed here will therefore be treated as more or less equal.

$\operatorname{Sex}$

Westoff and Potvin stated their original theory only with reference to girls, following their study of American college women. It has been assumed that the sex differential in family size preferences is a legiti=: mate topic for inquiry and that other hypotheses suggested by Westoff and Potvin might likewise apply to males. About half the samples in the fertility socialization literature are exclusively females, while the other half include both sexes.

Mixed findings have emerged in the studies examining male-female differentials. Some data show no consistent differences (van Tienhoven et al., 1971; Darney, 1970; Brackbill and Howell, 1974); others show females wanting more children (Nobbe, 1968; Gustavus, 1973).

This confusion of findings may be a function of the age at which the sex differential appears. Longitudinal data have indicated that the female preference for more children emerges rather late in adolescence (Gustavus, 1973). Studies that examine race and sex interaction find that black females want fewer children than black males, whereas this differential is reversed among whites (Paterson, 1972; Gustavus and Mommsen, 1973). This interactive effect, like the age pattern of sex differentials, may confound the findings reported above.

\section{Race}

Race is really part of a more general ethnic variable suggested by Westoff and Potvin to include also national origin. Only those authors have been able to give significant attention to the national origin aspect of ethnicity.

Most fertility socialization studies include an examination of racial variations, and in fact several studies have centered entirely on black- 
white differences in family size preferences (Kuvlesky and Obordo, 1969; Zelnik and Kantner, 1972; Gustavus and Mommsen, 1973). Black-white differentials seem to vary by age. Zelnik and Kantner and Gustavus and Mommsen report that the youngest blacks in their samples wanted fewer children than whites of similar ages. Among the oldest children, however, this differential reversed itself and paralleled

* the finding among adults that blacks have larger family size preferences than whites. The finding of age and race interaction is thus consistent, as is the finding that blacks nearer the age of fertility have higher family size preferences.

Zelnik and Kantner support this latter finding in their investigation of black-white differences in practices related to fertility, including age at which sexual activity begins, use of contraception, age at first marriage, and preferred birth intervals. The race differences in these factors suggest higher fertility for black women, even if the preferred size of families of blacks is lower than that of whites at early ages. Among older black girls, perception of these realities may create upward revision of family size desires and account for the age pattern above.

\section{Religion}

While specifically mentioned by Westoff and Potvin as important in explaining family size preferences, religion is usually analyzed only by differences between Catholics and non-Catholics. In spite of its limited definition, the variable is prevalent and, like race, has also been chosen for exclusive analysis (Potvin and Burch, 1969; Potvin and Lee, 1974; Brackbill and Howell, 1974).

In every fertility socialization study that includes Catholics and nonCatholics, the former want, prefer, intend, or desire more children for themselves than do the latter (Westoff and Potvin, 1967; Nobbe, 1968; Potvin and Burch, 1969; Gustavus and Nam, 1970; Gustavus, 1973; Potvin and Lee, 1974; Brackbill and Howell, 1974). The consistency of this finding even among sixth graders underscores the importance of religion in the formation of family size preferences. Brackbill and Howell (1974) have even argued that the data on religious differences in family size preferences among children contradict recent expecta-

- tions of narrowing religious differentials in actual fertility.

Some studies have also included children's religiosity (Paterson, 1972) and parents' religiosity (Nobbe, 1968). These variables were directly related to the size of family preferred by youngsters. 
Size of Family of Orientation

Westoff and Potvin suggested that size of the reference groups of girls would be influential in formation of family size preferences. Number of siblings or size of the family of origin, as it is alternatively labeled in the literature, has been almost the only measure of this more general variable. The inclusion of this variable is not universal but is relatively frequent.

The consistency of relationship between size of family of orientation and family size preferences is overwhelming, since all studies find the two directly related (Hendershot, 1967; Gustavus and Nam, 1970; Paterson, 1972; Gustavus, 1973; McLaughlin, 1974; Brackbill and Howell, 1974). Hendershot also included a measure of the actual family size preferences of mothers but found this variable less strongly related to a youngster's family size preference than the mother's actual fertility performance.

\section{Socioeconomic Status}

Westoff and Potvin noted class membership as an important influence on the formation of family size preferences. That suggestion has been operationalized by using father's occupation, father's education, income of parents, or, in the case of older samples, occupational intentions. This variable is not common in fertility socialization studies, perhaps owing to the difficulty of gaining access to school systems that represent a cross-section of socioeconomic status or owing to the nature of the school system itself.

When used, socioeconomic status appears negatively related to children's family size preferences, thus paralleling findings in the adult population. Relative to interactive effects, Brackbill and Howell (1974) found socioeconomic status positively related to family size preferences for Catholics and negatively related for non-Catholics, a finding also apparent among adults.

\section{Aspirations}

Westoff and Potvin suggested that changes between parents and their children in socioeconomic, educational, or role aspirations would produce instability in family size preferences. Fertility socialization studies, have not dealt with generational changes, but have examined aspirations conceptualized as desires for career or marriage for young girls, or desires for alternatives to traditional roles for women. In addition, some studies include standard measures of occupational or educational aspirations. 
Some form of aspiration variable is common in many studies and seems to be an increasingly popular variable as attention turns to changing women's roles and their impact on fertility. Use of these variables yields mixed findings. Educational aspirations were not related to family size preferences in the Gustavus and Nam study (1970), since their 1,123 young people exhibited little variation from high aspirations. Negative relationships of family size preferences and career aspirations were found by McLaughlin (1974) and Paterson (1972). Presser (1974) and Brackbill and Howell (1974) find no relationships between aspiration variables and family size preferences.

In a novel approach to the study of aspirations and family size expectations, McLaughlin found that young women with low fertility expectations perceived no role conflict between career and motherhood aspirations, whereas this conflict was apparent when large numbers of children were expected.

\section{Other Variables}

The discussion above includes the most common variables studied in relation to family size preferences among young people. A few investigations have studied unique variables but the relative infrequency of their inclusion makes statements about consistency of findings impossible. Such factors include population awareness (Brackbill and Howell, 1974; Wernick, 1974), birth control usage and at titudes (Zelnik and Kantner, 1972; Weiss et al., 1974), best friend's family size (Gustavus, 1968), previous pregnancy (Zelnik and Kantner, 1972), and mother's family size preference (Hendershot, 1967).

\section{Multivariate Approaches}

To measure the importance of a variable in explaining the formation or stability of family size preferences among children it has been necessary to rely on the frequency or consistency with which a relationship has appeared. This is because of the dearth of multivariate analyses in the fertility socialization literature.

Two published studies use path-analysis to predict the family size preferences of youngsters. Paterson (1972) includes nine measured variables and one hypothetical motivation variable to predict ideal family size in a sample of Louisiana high school senior men, and McLaughlin (1974) employs seven variables to predict expected family size among a sample of high school senior women in northwest Ohio. Neither researcher accounts for more than 10 percent of the variance in his dependent variable. In fact, Paterson's model explains educational expectations better than ideal fertility. 
Paterson's model includes father's occupation and education, size of family of orientation, and respondent's educational and occupational aspirations, I.Q., grade point average, and educational expectations. Of these, the largest single correlation with ideal fertility is size of family of orientation. The McLaughlin model contains variables more relevant to a sample of women: ideal female role type, status awareness relative to men, and a marriage-versus-career index, along with educational expectations, number of siblings, father's occupational prestige, and career plans. McLaughlin measures expected family size with an index computed by differentially weighting and combining a first, second, and third number of children expected. Trichotomizing the index into low, medium, and high, McLaughlin uses two dummy variables in the path model, representing the change from a low to a medium family size expectation, and a change from a medium to large expected family size. The second of these is used as the dependent variable in a revised path model, since significant paths could not be drawn between career aspirations and the first change in expected family size.

These two multivariate approaches to fertility socialization research are important beginnings, but they represent only a portion of what is needed. There is yet no study that gathers data on a large number of variables from a random and representative sample of American children and examines the relative importance of these variables in explaining family size preferences.

\section{THEORETICAL RELEVANCE}

At this point it seems useful to recall the original Westoff-Potvin theory of family size preference formation and summarize how the findings and methodologies evidenced in the seven years since its publication support, refute, or revise that work. It has already been noted that the literature has shown little overt concern with the WestoffPotvin scheme in its organization or conclusions. Rather, the contribution of the theory has been in suggesting hypotheses with which to begin research and in generating interest in fertility socialization in the first place.

\section{Approaches to Origins}

The most basic question posed by the fertility socialization literature has been, Where do family size preferences come from? As noted at the beginning of this paper, the motivation for investigating that ques- 
tion might be theory building, desire to in tervene in or modify the process, or predictive modeling. The preceding review indicates that every variable suggested by Westoff and Potvin as relevant to the origins of family size preferences, and subsequently tested, has been shown to be so related.

Besides these substantive findings, three strategies for ascertaining where family size preferences come from are apparent in the literature: the correlational approach, the conscious-sources approach, and the complementary interview.

The summary of findings presented above illustrates the correlational approach to the origins of family size preferences. Basically this tactic finds factors in the child's environment that are related to preferences and then infers causation. Thus, if consistent differences emerge between Catholic and non-Catholic youngsters, the inference is that church influences partially account for the origin of family size preferences. If females want more children than males; the correlational approach reasons that family size preferences partially originate in sex socialization. This strategy for assessing origins of family size preferences is clearly, the dominant one in the fertility socialization literature. This is not surprising given the ubiquity of the correlational approach in the general fertility literature.

The second strategy, called here the conscious-sources approach, is relatively infrequent in fertility socialization studies, while enjoying widespread use in fertility studies among adults. This strategy simply asks youngsters where they got their family size preferences, hoping they will be conscious of these sources and be able to articulate them. Studies using this approach ask children where they got an idea about numbers of children to have, or who they have actually talked to about a family size preference. By and large, the conscious-sources approach has not yielded very useful information. Reports of conversations on family size have been used like correlational data to reason influcnce on origins, though such causation has not been demonstrated. To direct-source questions children often respond with affirmations that it is their own idea, with answers that change so rapidly or randomly as to appear unreliable, or simply with silence (Gustavus, 1973).

The third approach, the complementary interview, gathers data from significant others in the child's environment in order to check on and supplement any or all of the data gathered in other ways. This approach has been infrequent but fruitful (Darney, 1970; Hendershot, 1972). The inconvenience and added expense of interviews with best friends, parents, siblings, ministers, or teachers are probably the chief 
reasons for the paucity of data of this kind. However, this strategy is methodologically useful for checking the accuracy of children's responses, as well as theoretically valuable in presenting a more complete picture of origins of family size preferences.

\section{Approaches to Stability}

Relative to origins, stability of family size preferences has been neglected in fertility socialization research. Two approaches have been used to assess stability: cross-sectional data analyzed by age, and longitudinal data.

Using cross-sectional data analyzed by age as an approximation of real aging is clearly inferior to true longitudinal analysis in assessing stability (Gustavus, 1973). The high school or college seniors of today are not simply the freshman of yesterday grown older, owing to selective attrition, particularly in school populations, variations in norms, and the general complex of social change factors. In the early stages of fertility socialization research, such analyses were useful, if only as beginning points in a field that had no data on stability of children's family size preferences.

The few longitudinal studies in existence suffer from the usual problems of sampling loss, short time spans covered, and their own infrequency limiting comparison. The most useful of these studies is the recent reanalysis of the Potvin and Burch data by Potvin and Lee (1974). These authors used standardization techniques to separate group and individual probabilities of change in family size preferences. While the original Westoff and Potvin theory suggested change in reference groups or in settings as a factor contributing to change in family ${ }_{1}$ size preferences, the Potvin and Lee analysis indicates the opposite. College women who had changed their school setting from Catholic to nonsectarian or vice versa, showed more adherence to earlier family size preferences than women who had remained in the same setting. Such a finding led Potvin and Lee to hypothesize a minority effect produced by changing settings, causing previous positions to be held more defensively than in familiar environments. If supported in other studies, this finding will require the first major revision of the Westoff-Potvin formulation of factors related to the stability of family size preferences.

\section{FUTURE DIRECTIONS}

The extended treatiment above requires only a summary here of the theoretical and methodological needs in fertility socialization. Al- 
though the Westoff-Potvin scheme has proved invaluable and essentially correct in guiding fertility socialization research in its infancy; a more complete model of socialization processes is needed. Adoption or creation of such a model would not only add cogency to the fertility socialization literature but could provide a general framework for other population socialization studies. The most general theories of socialization can be found in psychology and sociology. What characteristics are there of all preschool or adolescent children that we might find relevant to fertility socialization? What general socialization theories are there that we might use as broad frameworks in population studies?

The empirical work of other disciplines may be relevant as well. Ethnographic accounts of childhood in various cultures by anthropologists might broaden the perspectives of those examining population socialization in their own societies (Howard, 1974). Political scientists have developed an entire literature on the absorption of political attitudes and behaviors by children. Those in population studies can profit by their methodology, as well as their findings about the relevance of given variables. There is a literature on curricula, teaching methods, and suitable ages for learning different types of information. Child development specialists in education can communicate general views of youngsters. This is only a partial list of what might develop into profitable areas for collaboration.

The major methodological needs in fertility socialization research seem to be larger and more representative samples of young people, continuity in measurements, more use of multivariate analysis, inclusion of validity and reliability checks, and exploration with new variables. While previous approaches to measurement of origins and stability of family size preferences have been useful, new ways of getting at these crucial processes need to be identified. New indices, tactics, and procedures tailored to the needs and capabilities of young samples need to be explored and discussed (Rabin and Greene, 1968).

Several years ago the questions in this area were, Do children have family size preferences, and if so do these preferences mean anything now or later? These questions have now been answered affirmatively, and it is time to move from demonstrating mere existence of preferences among children to more sophisticated and theoretically relevant searches for factors that create and modify family size choices.

The emergence of population socialization as a field, and fertility socialization more particularly, represents the perhaps belated discovery that important topics like how many children to have, how and 
when to get health care, or why and when to migrate may be taught to children as part of their initiation into society. Knowledge of how this learning takes place is not only theoretically interesting, but also a clear prerequisite for effective intervention in this process for those interested in change. 


\section{REFERENCES}

Brackbill, Yvonne

1974 Test-retest reliability in population research. Studies in Family Planning 5(8):261-266.

Brackbill, Yvonne, and Embry M. Howell

1974 Religious differences in family size preference among American teenagers. Sociological Analysis 35(1):35-44.

Darney, Philip D.

1970 Attitudes of married college students on overpopulation and family planning. Public Health Report 85(5):412-418.

Farley, Jennie

$1970 \quad$ Graduate women: career aspirations and desired family size. American Psychologist 25(12): 1099-1100.

Gustavus, Susan O.

1968 The formation and stability of ideal family size norms among young people. Unpublished Ph.D. dissertation, Department of Sociology, Florida State University.

1973 The fannily size preferences of young people: a replication and follow-up study. Studies in Family Planning 4(12):335-342.

Gustavus, Susan O., and Kent G. Mommsen.

1973 Black-white differentials in family size preferences among youth. Pacific Sociological Review 16(1): 107-119.

Gustavus, Susan O., and Charles B. Nam

1970 The formation and stability of ideal family size among young people. Demography 7(1):43-51.

Hendershot, Gerry E.

1967 Fertility value in two generations. Paper presented at annual meeting of the Population Association of America, Cincinnati.

1969 Family satisfaction, birth order, and fertility values. Journal of Marriage and the Family 31(1):27-33.

Howard, Alan

1974 Role programming for large family size: the case of HawaiianAmericans. Paper presented at annual meeting of the Population Association of America, New York. 
Kuvlesky, W.P., and S.A. Obordo

1969. Racial differences in teenage girls' orientations toward marriage: a study of youth living in an economically depressed area of the South. Paper presented at annual meeting of the Southern Sociological Association, New Orleans.

McLaughlin, Steven

1974 Expected family size and perceived status deprivation among high school senior women. Demography 11(1):57-73.

Nam, Charles B., and Morgan I. Lyons

1974 Early life cycle changes in residential mobility orientations. Paper presented at annual meeting of the Population Association of America, New York.

Nobbe, Charles E.

1968 Correlaies of desired family size among college educated Catholics. Unpublished Ph.D. dissertation, Department of Sociology, University of Washington.

Palmore, James A.

$1974 \quad$ United States. In Henry P. David and Sung Jin Lee (eds.), Social and Psychological Aspects of Fertility in A sia. Proceedings of The Technical Seminar, Transnational Family Research Institute, Choonchun, Korea, November 1973.

Paterson, Neil

1972 Adolescent family size preferences. International Journal of Sociology of the Family 2(2):231-245.

Potvin, R., and Thomas Burch

1969 Catholic college women and family-size orientations: a panel study. Paper delivered at annual meeting of the American Catholic Sociological Association, Boston.

Potvin, R., and Che-Fu Lee

1974 Catholic college women and family-size preferences: a reanalysis. Sociological Analysis 35(1):24-34.

Presser, Harriet B.

1974 Sex-role socialization for motherhood. Paper presented at annual meeting of the Population Association of America, New York.

Rabin, A.J., and Robert J. Greene

1968 Assessing motivation for parenthood. The Journal of Psychology 69(1):39-46. 
Russo, Nancy F., and Yvonne Brackbill

1973 Population and youth. In James T. Fawcett (ed.), Psychological Perspectives on Population, pp. 393-427. Basic Books: New York.

Tavuchis, Nicholas

1970 Youth and population. Unpublished report to the Population Council.

van Tienhoven, A.; T. Eisner; and F. Rosenblatt

1971 Education and the population explosion. BioScience 21(1):16-21.

Weiss; Eugene; F. Gcrald Kline; Everett M. Rogers; Mitchel E. Cohen; and Jennifer A. Dodge

$1974^{\circ}$ Communication and population socialization among youth: communication behavior and family planning information. Paper presented at annual meeting of the Population Association of America, New York.

Wernick, Peter

1974 Determinants of teenagers' family size preferences: the tesing of a theory. Paper presented at the Conference on Population Socialization held at the East-West Population Institute in December 1974.

Westoff, Charles F., and Raymond H. Potvin

1966 Higher education, religion, and women's family size orientations. American Sociological Review 31(4):489-496.

1967 College Women and Ferility Values. Princeton: Princeton Universily Press.

Zelnik, Melvin, and Jolnn F. Kantner

1972 Some preliminary observations on pre-adult fertility and family. formation. Studies in Family Planning 3(4):59-65. 
No.

3 Husband-wife interaction and family planning acceptance: a survey of the literature, by Florangel Z. Rosario, November 1970, 21 pp.

9 Linkages of intrinsic to age-specific rates, by Nathan Keyfitz, December 1970, 33 pp. [Now available as Reprint 14.]

10. Methods of demographic estimation for statistically underdeveloped areas, by Paul Demeny, January 1.971, 149 pp. [Now available as Reprint 17.]

12 Interpersonal communication and the diffusion of family planning in West Malaysia, by James A. Palmore, Paul M. Hirsch, and Ariffin bin Marzuki, March 1971, 33 pp. [Now available as Reprint 13.]

15. Measuring mortality: a self-teaching guide to elementary measures, by James A. Palmore, May 1971, revised June 1973, 61 pp.

16 Measuring fertility and natural increase: a self-teaching guide to elementary measures, by: James A. Palmore, May 1971, revised October 1972, 81 pp.

18. On aggregative economic models and population policy, by Geoffrey McNicoll, October $197.1,87 \mathrm{pp}$.

19 Households, families and friends in a Hawaiian-American community, by Alan Howard, November 1971, $117 \mathrm{pp}$.

21 Multivariate analysis of areal fertility in Honolulu, by Chai Bin Park, March 1972, 39 pp.

23 A model for the age distribution of first marriage, by Griffith M. Feeney, April 1972, $31 \mathrm{pp}$.

26 Spatial patterns of socio-economic structure and change in the Philippines, 1939-60, by Roland J. Fuchs and Telesforo.W. Luna, Jr., August 1972, 55 pp.

27. Representation of national and regional political units in a computerized world future model, by. Peter Maggs, October 1972, 51 pp.

28 The demographic situation in Indonesia, by Geoffrey McNicoll and Si Gde Made Mamas, December 1973, $68 \mathrm{pp}$.

29 The demographic situation in the Republic of Korea, by Leelay Cho, December 1973 , $52 \mathrm{pp}$.

30 Demographic research in Japan, 1955-70: a survey and selected bibliography, by $Y$. Scott Matsumoto, April 1974, 88 pp.

31 The demographic situation in Hawaii, by Robert W. Gardner and Eleanor C. Nordyke, June 1974, 120 pp.

32 The value of children in Asia and the United States: comparative perspectives, by James $T$. Fawcett et al., July 1974, 80 pp.

33 The present and prospective state of policy approaches to fertility, by Ozzie G. Simmons and Lyle Saunders, June 1975, 32 pp.

34 Female labor force participation in a modernizing society: Malaya and Singapore, 19211957 , by.Monica S. Fong, June 1975, 48 pp. 

